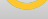

\title{
Measuring Financial Protection in Hospitalized Patients after the Health Sector Evolution Plan in Iran
}

\author{
Soheyla Reshadat, ${ }^{1}$ Farid Najafi, ${ }^{2}$ Behzad Karami-Matin, ${ }^{3}$ Moslem Soofi,,${ }^{4}$ Eshagh Barfar, ${ }^{5}$ Nader \\ Rajabi-Gilan, ${ }^{6}$ and Seyed-Ramin Ghasemi ${ }^{7}$ \\ ${ }^{1}$ Associate Professor of Pediatrician, Social Development and Health Promotion Research Center, Kermanshah University of Medical Sciences, Kermanshah, IR Iran \\ ${ }^{2}$ Professor of Epidemiology, Research Center for Environmental Determinants of Health, Kermanshah University of Medical Sciences, Kermanshah, IR Iran \\ ${ }^{3}$ Associate Professor of Health Management, Research Center for Environmental Determinants of Health, Kermanshah University of Medical Sciences, Kermanshah, IR Iran \\ ${ }^{4} \mathrm{PhD}$ Student of Health Economics, Social Development and Health Promotion Research Center, Kermanshah University of Medical Sciences, Kermanshah, IR Iran \\ ${ }^{5} \mathrm{PhD}$ Student of Health Economics, Health Promotion Research Center, Zahedan University of Medical Sciences, Zahedan, IR Iran \\ ${ }^{6}$ M.Sc. of Social Research, Social Development and Health Promotion Research Center Kermanshah University of Medical Sciences, Kermanshah, IR Iran \\ ${ }^{7}$ M.Sc. of Social Welfare, Social Development and Health Promotion Research Center, Kermanshah University of Medical Sciences, Kermanshah, IR Iran \\ "Corresponding author: Moslem Soofi, Social Development and Health Promotion Research Center, Kermanshah University of Medical Sciences, Kermanshah, IR Iran. Tel: \\ +98-9186802180, Fax: +98-8314216143, E-mail: moslemsoofi@yahoo.com
}

Received 2016 September 08; Revised 2017 January 07; Accepted 2017 February 23.

\begin{abstract}
Background: Protecting people from catastrophic health payments is widely recognized as an integral component of health systems and universal health coverage.

Objectives: This study aimed to measure the financial protection against catastrophic health expenditure among hospitalized patients in Kermanshah, western Iran, after the implementation of the health sector evolution plan of Iran.

Methods: This was a cross-sectional study. A total of 544 patients were selected using the proportional allocation to population size technique. A translated version of the world health survey questionnaire was used to collect data. Catastrophic health expenditure was calculated using WHO recommended methodology. Data were analyzed using STATA v.13. The statistical test performed included descriptive statistics and logistic regression.

Results: About $4.8 \%$ of households with hospitalized patients were faced with catastrophic health expenditures. The total mean outof-pocket (OOP) medical expenditures of being hospitalized was 819,220 Rials per patient. Mean OOP in patients with catastrophic payment was 2,220,500 Rial. Major determinants of catastrophic payment were associated with surgical cost (OR: 8.09 P Value = $0.000)$, chronic disease (OR:2.78 P Value $=0.025)$, household size $(>6)(\mathrm{OR}: 6.70$ PValue $<0.036)$, and economic status of households (Quintile 5; OR: 0.005 P Value $=0.000$ ).

Conclusions: The Health Sector Evolution Plan should target and extend aids especially for chronically ill patients, those who need surgery, and those at poorest quintile due to the fact that they are more vulnerable to catastrophic health expenditure. These groups should be the priorities in the health sector evolution plan revision to achieve a more desired outcome.
\end{abstract}

Keywords: Financial Protection, Catastrophic Health Expenditure, Out-of-Pocket Payment, Hospitalized Patients, Health Reform

\section{Background}

Worldwide, millions of people suffer from financial hardship due to out-of-pocket (OOP) health payments (1). As a result, the concept of financial risk protection remains a major focus of many health systems $(2,3)$ and is a core component of universal health coverage (UHC) (1). Financial protection is defined as access to needed and good quality health services without financial catastrophe. One of the common indicators of financial protection is incidence of catastrophic expenditure due to health payments (1). OOP payment defines as catastrophic if it exceeds a certain threshold of the household consumption expenditure, the income, or the capacity to pay in a given period $(4,5)$. The threshold of $40 \%$ of capacity to pay widely has applied in the empirical studies (6).

High OOP payments for health care deter people, especially the poor from receiving needed health services due to the fact that they cannot afford to pay for them $(3,7)$. Often, poorer households are forced to borrow, sell assets, reduce consumption, or resort to their savings in order to pay for health care cost, leading to penury $(3,8,9)$. Impact of catastrophic OOP payments for health services is a major challenge to households, especially in the low and mid- 
dle income countries as well as OECD countries (6). A wellfunctioned health system maintains a balance of ensuring that individuals are able to have access to improved health services without facing financial consequences $(4,6,9)$. For this reason, measures to prevent catastrophic health expenditure and provision of quality care are of great concern to all countries, institutions, and the academia (1). High OOP payment was a major challenge to the people of Iran and many Iranians were unable to afford the cost in seeking for health care due to it (10). Previous studies in Iran have shown that the incidence of catastrophic health expenditures (CHE) ranges from $6 \%-17.7 \%$ at the national level $(11,12)$, and $14.2 \%-22.2 \%$ at the regional level $(13,14)$, with an OOP payment of about $52.1 \%$ (15). To address this challenge, in 2014, the government of Iran took a bold health reform initiative by instituting the health sector evolution plan (HSEP) (16). More than 3 billion US dollars have been allocated to improve the Iran health system. Sources of funds include $1 \%$ value-added tax, $10 \%$ of targeted subsidies, and partial general revenue of the government (17).

The main goals of the HSEP was to ensure that everyone has access to health insurance, reduce OOP payments for inpatient services, provide financial protection to patients with specific diseases (such as hemophilia, thalassemia, renal replacement therapy) and poor users, motivate medical doctors to stay in deprived areas of the country, improve quality of care by increasing specialists, as well as improving hospital amenities and lodging services $(17,18)$.

Although some studies have measured CHE in Iran before the HSEP, only tiny literature exist to explain the reduction of OOP payments and catastrophic expenditures after the HSEP. Besides, consistent assessment of financial risk protection, preferably every 2 to 5 years, has been recommended to evaluate and monitor the effect of policy intervention and reform (1).

\section{Objectives}

This study aimed to measure the financial protection against health costs within households with hospitalized patients after the HSEP in Kermanshah, Iran. We anticipate findings will help to improve the HSEP and financial protection against health costs in Iran.

\section{Methods}

This cross-sectional study was conducted on patients discharged from university hospitals in Kermanshah city, western Iran, in 2015. The city has 7 public university hospitals ( 2 general and 5 specialized hospitals) with a total number of 1570 active beds and 2 private hospitals. Data was gathered from the 7 public university hospitals. A total sample of 544 patients was calculated using the single proportion formula, where $\mathrm{p}=15 \%$ (the mean proportion of the households faced with CHE in previous regional studies in Iran, $\mathrm{d}=3 \%$ (margin of error) and $\alpha=0.05$ (Type I error). We used the proportional allocation to population size technique in collecting data from each hospital. For each hospital, we selected participants proportional to the number of hospital beds.

Data was collected using a translated version of a questionnaire proposed by the world health organization (WHO) (19). The validity and reliability of translated questionnaire were determined and verified by Kavosi et al. (20). The questionnaire covers individual and household level data. Data on demographic features of hospitalized patients as well as their household heads, food expenditure, total household expenditure on goods and services, household size and OOP health expenditures made by patients or their households at the point of receiving hospital services (mainly charges for health care services, laboratory and diagnostic tests, drugs, and medical equipment) to calculate the proportion of catastrophic health expenditures. In addition, we included a few questions in the questionnaire. For example, patients were asked whether they had surgery and also asked about their length of hospital stay. Therefore, for greater certainty, we calculated Cronbach's alpha for the 40 first samples and its reliability was confirmed with 0.81 . An adult family member who followed the patient's discharge process was asked to fill the questionnaires on behalf of patients who were unable to complete the questionnaire due to the condition of their disease. All patients or their family members agreed to participate in the study either orally or in writing. Data collection started from mid September 2015 to mid December 2015.

We used capacity to pay (CTP) (non-subsistence spending) in calculating catastrophic spending (21). CHE was defined when OOP payments on health equal or exceed $40 \%$ of household's capacity to pay or non-subsistence spending. CTP is defined as an effective income minus subsistence spending. To reduce the likelihood of short-term fluctuations in income data, total household expenditure was used as the proxy for effective income (22). In this study, CTP is the difference between total household spending and subsistence expenditure. Subsistence expenditure was calculated as the average food spending of the households whose food share fall within the 45th to 55th percentile range across the whole sample, however adjusted based on size of household (21). Households whose OOP medical payments exceed $40 \%$ of its CTP were classified to experience catastrophic health expenditures. 
A logistic regression model was used to assess the determinants of catastrophic health expenditures. This model is a special type of regression that is applied for binary-outcome variables. In the binary dependent variable model, a predicted value of 1 depicts that households are faced with catastrophic health expenditure, while 0 means that they are not faced with such expenditures. Independent variables commonly used in related studies, both national and international, were also included in the model $(3,5,23,24)$. They include place of residence, sex of house head, expenditure quintile, size of household, and number of member(s) who were chronically sick. We used the odds ratio to interpret the effect size of predictor variables. The STATA v.13 was used to analyze the data. The study protocol was approved by the ethics committee of Kermanshah University of Medical Sciences

\section{Results}

Overall, 416 out of 544 participants (76.4\%) completed the questionnaires. The mean age of patients was 38.92 years. The majority (54.8\%) of study participants were female. Furthermore, $46.1 \%$ of our interviewees have acquired middle/high school education. The mean length of stay was 10.59 days. However, almost 32.1\% of participants had a surgical operation during their stay. Moreover, about $32.1 \%$ of the patients reported that other household members need chronic health care. Approximately, $97.6 \%$ of the patients had health insurance coverage. Majority (78.1\%) of participants resided in urban area. The mean of household size was 4.54 . About 52.5\% participants were within the low and middle economic status (Table 1 ).

According to our findings, almost $4.8 \%$ of patients experienced catastrophic health expenditures due to OOP payments. We also did not observe the incidence of catastrophic health expenditures in the psychiatric and obstetrics hospitals ( $\mathrm{B}$ and $\mathrm{F}$ ). While the total mean OOP health expenditures of being hospitalized was 819,220 (1,623,930) Rials per patient, that of patients with catastrophic payment was 2,220,500 $(1,967,320)$ Rials (at the time of this study, \$1 was equal to 34,000 Iranian Rials (IRR)) (Table 2).

Table 3 presents the estimated odds ratio from a logistic regression model for $40 \%$ catastrophic threshold. Catastrophic health expenditures were found to be statistically significantly associated with households whose members reported of suffering from at least 2 chronic diseases $(\mathrm{OR}=4.29 ; 95 \% \mathrm{CI}=1.20-15.29)$. Results also revealed that, the odds of facing catastrophic health expenditures was about 8 times higher among households where their hospitalized member had undergone surgery ( $\mathrm{OR}=8.09$; 95\% CI = 2.59 - 25.23). Moreover, larger households (> 6 members) were statistically significantly more
Table 1. Descriptive Results of the Sample Hospitalized Patients in the Seven Public University Hospitals in Kermanshah, Iran, 2015

\begin{tabular}{|c|c|}
\hline Variables & Values $^{\mathrm{a}}$ \\
\hline Age & $45.99 \pm 16.91)$ \\
\hline Number of Hospitalizations Days & $10.80 \pm 5.84)$ \\
\hline Size of households & $4.54 \pm 1.65)$ \\
\hline \multicolumn{2}{|l|}{ Level of education } \\
\hline Illiterate and primary school & $226(53.8)$ \\
\hline Middle And high school & $135(33.3)$ \\
\hline Academic & $54(12.9)$ \\
\hline \multicolumn{2}{|l|}{ Job of house heads } \\
\hline Unemployed & $100(23.8)$ \\
\hline Employee & $54(12.9)$ \\
\hline Self-employer & $174(41.4)$ \\
\hline Other & $92(21.9)$ \\
\hline Having chronic disease & $(32.9)$ \\
\hline households headed by female & $(6.2)$ \\
\hline Urban Residents & $328(78.1)$ \\
\hline Having Surgery & $141(33.5)$ \\
\hline Having Insurance Coverage & $410(97.6)$ \\
\hline Female Gender & $230(54.8)$ \\
\hline \multicolumn{2}{|l|}{ Household Head's educational level } \\
\hline Illiterate and primary school & $146(34.8)$ \\
\hline Middle And high school & $190(45.2)$ \\
\hline Academic & $84(20)$ \\
\hline \multicolumn{2}{|l|}{ Household expenditures quintiles } \\
\hline 1st Quintile & $4(1)$ \\
\hline 2nd Quintile & $78(18.6)$ \\
\hline 3rd Quintile & $138(32.9)$ \\
\hline 4th Quintile & $74(17.6)$ \\
\hline 5th Quintile & $126(30)$ \\
\hline
\end{tabular}

${ }^{\mathrm{a}}$ Variables are expressed as mean $\pm \mathrm{SD}$ or No. (\%).

likely to face catastrophic health expenditures $(\mathrm{OR}=7.14$; 95\% CI= $1.13-45)$. With an increasing household size, the likelihood of facing catastrophic health expenditures increased. Households within the higher expenditure quintile were significantly less likely to face catastrophic expenditure compared with the lower quintile, and with increasing households' monthly expenditure, the likelihood of facing catastrophic health expenditures declines. Household heads aged over 65 years; the sex of house heads and place of residence had no statistically significantly relationship with the likelihood of catastrophic payment. The 
Table 2. Rate of Occurrence of Catastrophic Health Expenditures and Mean Out-ofPocket Expenditures in Participants in Kermanshah, Iran, 2015

\begin{tabular}{lccc}
\hline Hospital & Patients $^{\mathbf{a}}$ & Pocket Expenditure $^{\mathbf{b}}$ & Pocket Expenditure $^{\mathbf{c}}$ \\
\hline A & 8.70 & $1642390(1556250)$ & $1292500(94290)$ \\
\hline B & 0.00 & $217220(396750)$ & - \\
\hline C & 3.33 & $867330(1021890)$ & $1005000(63630)$ \\
\hline D & 5.00 & $893730(760910)$ & $2475000(247480)$ \\
\hline E & 4.00 & $581600(1045490)$ & $4350000(989940)$ \\
\hline F & 0.00 & $479420(942960)$ & - \\
\hline G & 6.85 & $812000(2260270)$ & $2384000(2492780)$ \\
\hline Total & 4.8 & $819220(1623930)$ & $2220500(1967320)$ \\
\hline
\end{tabular}

${ }^{\text {a }}$ Percentage of patients experiencing catastrophic health expenditures

${ }^{\mathrm{b}}$ Mean out of pocket expenditure in Rials (SD).

${ }^{\mathrm{c}}$ Mean out of pocket expenditure among patients with catastrophic payments in Rials (SD).

model goodness-of-fit based on the Hosmer-Lemeshow test was satisfactory with $40 \%$ threshold levels.

\section{Discussion}

This study aimed to measure financial protection against catastrophic health expenditures among households whose member was hospitalized after the HSEP of Iran. By comparison with pre-reform, the findings suggested that the exposure to catastrophic expenditure has been decreased. However, catastrophic health expenditures have yet been remained in some cases, which will be discussed in this section.

Catastrophic health expenditures, as identified in our study, was lower compared to the findings of previous studies, which were conducted before the HSEP in Kermanshah (22.2\%) (13) as well as Tehran (15.6\%) (23). Catastrophic health expenditures were not experienced by patients in the psychiatric and obstetrics hospitals. In the obstetrics hospital, this may be because of financial protection of HSEP for normal delivery and lower length of stay in this hospital. In the psychiatric hospital, one reason may be due to the fact that services and procedures are relatively less expensive and therefore it is cheaper in these types of hospitals. A study by Piroozi et al. after the implementation of HSEP, also revealed similar incidence of catastrophic health expenditures, i.e. about 5\% among households in the Kurdistan province (25). Furthermore, according to a study by Limwattananon et al. in Thailand, the percentage of exposure to catastrophic expenditures for households using inpatient care was 31.0\% in 2000 (before universal coverage), compared with $15.1 \%$ and $14.6 \%$ in 2002 and 2004 (after universal coverage), respectively (26).
A study after health transformation plan (HTP) in Turkey also revealed a decreasing trend of catastrophic health expenditures during 2003 - 2009. CHE was $0.75 \%$ in 2003 and $0.59 \%$ as well as $0.48 \%$ in 2006 and 2009 , respectively (27).

In our study, the mean out of pocket payment for all patients and patients who faced catastrophic payment were $819,220(1,623,930)$ and 2,220,500 $(1,967,320)$ Rials, respectively, i.e. lower than what the study has revealed in Tehran before Iran's health reform (23). The decrease in the OOP was mainly due to the fact that all needed drugs and equipment are now funded through the HSEP. A household survey conducted by Somkotra et al. on payments for health care and its effect on catastrophe and impoverishment on Thai households, also revealed a fall in OOP after their UHC reforms (28).

According to our study, households whose members had undergone surgical operation were significantly more likely to incur catastrophic health expenditures. A modeling study on catastrophic expenditure to pay for surgery worldwide showed that each year, approximately 33 million people worldwide suffer from catastrophic expenditure due to surgical care and almost 3.7 billion people will experience catastrophic payment if they undergo surgery treatments (2). A study by Nguyen et al. in Vietnam, on surgical cost and catastrophic expenditure among hospitalized patients with injuries, showed a substantial financial burden of households due to surgery. Moreover, surgery was strongly associated with risk of catastrophic health payments (29). Although most inpatient services are greatly financed by the government, the incidence of catastrophic OOP expenditure remains among those who need surgical treatments. Therefore, the government of Iran should improve the benefit package of patients who need surgical operations as well as the less privileged citizens. One probable reason for this result is that only the direct cost of health services were considered in our study. Although non-medical costs, such as transportation, accommodation, and food are important contributors of catastrophic expenditure and OOP medical payment (3), they were excluded from this research.

Catastrophic health expenditures were found to be statistically significantly associated within households having at least 2 chronic diseases. Studies have also revealed that having members with chronic diseases in the household increases risk of catastrophic expenditure (3, 6, 20, 3032). Besides, findings of post-reform study in Iran showed that the presence of disabled members in the household induced catastrophic payments even after the HSEP (25). Chronic diseases substantially put a huge financial burden on household budgets due to the fact that chronically ill patients are subjected to routine and long-term visits, testing, as well as medications and therefore, households' abil- 
Table 3. Logistic Regression of Incurring Out-of-Pocket Health Expenditures and Its Determinants in Participants in Kermanshah, Iran, 2015 $5^{\mathrm{a}, \mathrm{b}}$

\begin{tabular}{|c|c|c|c|c|}
\hline Variables & Odds Ratio & Std. Err. & $\mathbf{P}>|\mathbf{z}|$ & $(95 \% \mathrm{CI})$ \\
\hline \multicolumn{5}{|l|}{ Dependent variable $^{c}$} \\
\hline \multicolumn{5}{|l|}{ Independent Variables } \\
\hline Hospitalization day number & 1.06 & 0.044 & 0.146 & $(0.978-1.15)$ \\
\hline Having surgery & 8.09 & 4.69 & 0.000 & $(2.59-25.23)$ \\
\hline Having at least 2 chronic diseases & 4.29 & 2.78 & 0.025 & $(1.20-15.29)$ \\
\hline Gender of house heads & 0.759 & 0.891 & 0.815 & $(0.075-7.59)$ \\
\hline House heads aged over 65 years & 0.480 & 0.361 & 0.330 & $(0.110-2.09)$ \\
\hline Settlement & 0.563 & 0.377 & 0.392 & $(0.151-2.09)$ \\
\hline \multicolumn{5}{|l|}{ Household size } \\
\hline $3-6$ & 0.460 & 0.374 & 0.341 & $(0.093-2.27)$ \\
\hline$>6$ & 7.14 & 6.70 & 0.036 & $(1.13-45.00)$ \\
\hline \multicolumn{5}{|l|}{ Household expenditures quintile } \\
\hline Quintile2 & 0.076 & 0.101 & 0.052 & $(0.005-1.02)$ \\
\hline Quintile 3 & 0.041 & 0.050 & 0.009 & $(0.003-0.453)$ \\
\hline Quintile 4 & 0.005 & 0.008 & 0.001 & $(0.0002-0.126)$ \\
\hline Quintile 5 & 0.003 & 0.005 & 0.000 & $(0.0001-0.0733)$ \\
\hline
\end{tabular}

ity to pay for cost of hospitalization is decreased (33). Our findings indicate that the governments' financial support for hospitalization care is not effective in targeting people who need the services. Moreover, we found that households with more than 6 members were significantly more likely to face catastrophic health expenditures. This was consistent with findings of studies that were conducted in Egypt, Serbia, and China $(6,31,34)$. That is, as size of households increased, patients were statistically significantly more likely to spend more than $40 \%$ of their capacity to pay on hospital charges. Our findings also revealed a higher incidence of catastrophic health expenditures among low and middle-expenditures households. Result showed that households belonging to lower expenditure quintiles were significantly more likely to face catastrophic health expenditures. However, as supported by previous studies (23, 27, 30-32), catastrophic medical expenses decreased as household's quintile expenditure increased. Also, according to finding of one post-reform study, households with low economic status are more likely to experience CHE (25). In addition, HSEP should target and extend aids to poor patients who are more vulnerable to catastrophic health expenditures. In our study, male house heads, number of hospitalization days, place of resistance, sex of heads of household, and house heads who are over 65 years of age, were not statistically significant risk factors of catastrophic expenditure. On the other hand, some studies have revealed place of residence $(5,6,35)$ and house heads over $65(36)$ as significant determinants of catastrophic expenses, which were not consistent with our findings.

Our study has some limitations. For example, we only investigated catastrophic health expenditures based on hospitalization costs experienced by patients or their households, without considering post and pre-hospital costs (indirect cost). Additionally, this study was conducted in Kermanshah city, western Iran. That is, our incidence rate of CHE might not be the true representation of the overall incidence rate after the HSEP in Iran. As such findings should be interpreted with caution. We therefore recommended further research to investigate the magnitude of catastrophic expenditures due to both inpatient and outpatient services, especially after HSEP in Iran.

\subsection{Conclusions}

After the HSEP, the role of government in financial protection has been increased considerably. By comparison with pre-reform studies, OOP and catastrophic expenditures have been decreased. However, significant gaps exist within the health system of Iran and catastrophic health expenditure has yet been experienced. HSEP should target 
and extend aids especially for chronically ill patients, those who need surgery, and those at poorest quintile since they are more vulnerable to catastrophic health expenditure. These groups should be the priorities in HSEP revision to achieve more desired outcome.

\section{Acknowledgments}

The authors would like to thank the deputy for research and technology of the Kermanshah University of Medical Sciences for funding this research and also all participants and staffs at the various hospitals for their contributing to this study.

\section{Footnotes}

Authors' Contribution: The overall implementation of this study including design, data analysis, and manuscript preparation was the results of joint efforts by individuals who are listed as coauthors of this paper. All authors have made extensive contributions to the review and finalization of this manuscript.

Financial Disclosure: There is no conflict of interest.

Funding/Support: The study was a research project supported financially by the deputy for research and technology of the Kermanshah University of Medical Sciences.

\section{References}

1. Saksena P, Hsu J, Evans DB. Financial risk protection and universal health coverage: evidence and measurement challenges. PLoS Med. 2014;11(9):e1001701. doi: 10.1371/journal.pmed.1001701. [PubMed: 25244520].

2. Shrime MG, Dare AJ, Alkire BC, O'Neill K, Meara JG. Catastrophic expenditure to pay for surgery worldwide: a modelling study. Lancet Glob Health. 2015;3 Suppl 2:S38-44. doi: 10.1016/S2214-109X(15)700859. [PubMed: 25926319].

3. Xu K, Evans DB, Kawabata K, Zeramdini R, Klavus J, Murray CJL. Household catastrophic health expenditure: a multicountry analysis. Lancet. 2003;362(9378):111-7. doi: 10.1016/s0140-6736(03)13861-5.

4. Wagstaff A. Measuring financial protection in health. World Bank Publications; 2008.

5. Ozgen Narci H, Sahin I, Yildirim HH. Financial catastrophe and poverty impacts of out-of-pocket health payments in Turkey. Eur $J$ Health Econ. 2015;16(3):255-70. doi: 10.1007/s10198-014-0570-z. [PubMed: 24566703].

6. Arsenijevic J, Pavlova M, Groot W. Measuring the catastrophic and impoverishing effect of household health care spending in Serbia. Soc Sci Med. 2013;78:17-25. doi: 10.1016/j.socscimed.2012.11.014. [PubMed: 23267776]

7. Tomini SM, Packard TG, Tomini F. Catastrophic and impoverishing effects of out-of-pocket payments for health care in Albania: evidence from Albania Living Standards Measurement Surveys 2002, 2005 and 2008. Health Policy Plan. 2013;28(4):419-28. doi:10.1093/heapol/czs073. [PubMed: 22907092].

8. Kim Y, Yang B. Relationship between catastrophic health expenditures and household incomes and expenditure patterns in South Korea. Health Policy. 2011;100(2-3):239-46. doi: 10.1016/j.healthpol.2010.08.008. [PubMed: 20832893].
9. Wagner AK, Graves AJ, Reiss SK, Lecates R, Zhang F, Ross-Degnan D. Access to care and medicines, burden of health care expenditures, and risk protection: results from the World Health Survey. Health Policy. 2011;100(2-3):151-8. doi: 10.1016/j.healthpol.2010.08.004. [PubMed: 20828854].

10. Hosseinpoor AR, Bergen N, Koller T, Prasad A, Schlotheuber A, Valentine $\mathrm{N}$, et al. Equity-oriented monitoring in the context of universal health coverage. PLoS Med. 2014;11(9):e1001727. doi: 10.1371/journal.pmed.1001727. [PubMed: 25243463].

11. Ghiasvand H, Abolghasem Gorji H, Maleki M, Hadian M. Catastrophic Health Expenditure Among Iranian Rural and Urban Households, 2013 - 2014. Iran Red Crescent Med J. 2015;17(9):e30974. doi: 10.5812/ircmj.30974. [PubMed: 26473081].

12. Soofi M, Rashidian A, Aabolhasani F, Akbari Sari A, Bazyar M. Measuring the Exposure of Households to Catastrophic Healthcare Expenditures in Iran in 2001: the World Health Organization and the World Bank's Approach. J Hospital. 2013;12(2):39-50.

13. Karami M, Najafi F, Karami Matin B. Catastrophic health expenditures in kermanshah, west of iran: magnitude and distribution.J Res Health Sci. 2009;9(2):36-40. [PubMed: 23344170].

14. Kavosi Z, Keshtkaran A, Hayati R, Ravangard R, Khammarnia M. Household financial contribution to the health System in Shiraz, Iran in 2012. Int J Health Policy Manag. 2014;3(5):243-9. doi: 10.15171/ijhpm.2014.87. [PubMed: 25337598].

15. Mousavi SM, Sadeghifar J. Universal health coverage in Iran. Lancet Glob Health. 2016;4(5):e305-6. doi: 10.1016/S2214-109X(16)00068-1. [PubMed: 27102193].

16. Ministry of Health and Medical Education (MoHME). Health Sector Evolution Portal 2016. Available from: http://tahavol.behdasht.gov.ir/ index.aspx? fkeyid $=\&$ siteid $=426 \&$ pageid $=52443$.

17. Moradi-Lakeh M, Vosoogh-Moghaddam A. Health Sector Evolution Plan in Iran; Equity and Sustainability Concerns. Int J Health Policy Manag. 2015;4(10):637-40. doi: 10.15171/ijhpm.2015.160. [PubMed: 26673172].

18. Najafi F, Karami-Matin B, Rezaei S, Rajabi-Gilan N, Soofi M. Health system responsiveness after health sector evolution plan (HSEP): An inpatient survey in Kermanshah in 2015. Med J Islamic Republic Iran. 2016;30:387.

19. Murray CJL, Xu K, Klavus J, Kawabata K, Hanvoravongchai P, Zeramdini R. Assessing the distribution of household financial contributions to the health system: concepts and empirical application. In Health Systems Performance Assessment: Debates, Methods and Empiricism. Geneva: World Health Organization; 2003. pp. 513-32.

20. Kavosi Z, Rashidian A, Pourreza A, Majdzadeh R, Pourmalek F, Hosseinpour AR, et al. Inequality in household catastrophic health care expenditure in a low-income society of Iran. Health Policy Plan. 2012;27(7):613-23. doi: 10.1093/heapol/czs001. [PubMed: 22279081].

21. Xu K. Distribution of health payments and catastrophic expenditures methodology Genva: World Health Organization; 2005. Available from: http://www.who.int/iris/handle/10665/69030.

22. Koltai PI, Solares CA, Koempel JA, Hirose K, Abelson TI, Krakovitz PR, et al. Intracapsular tonsillar reduction (partial tonsillectomy): reviving a historical procedure for obstructive sleep disordered breathing in children. Otolaryngol Head Neck Surg. 2003;129(5):532-8. doi: 10.1016/S0194-59980300727-7. [PubMed: 14595276].

23. Ghiasvand H, Sha'baninejad H, Arab M, Rashidian A. Hospitalization and catastrophic medical payment: evidence from hospitals located in Tehran. Arch Iran Med. 2014;17(7):507-13. [PubMed: 24979565].

24. Xu K, Evans DB, Kadama P, Nabyonga J, Ogwal PO, Nabukhonzo P, et al. Understanding the impact of eliminating user fees: utilization and catastrophic health expenditures in Uganda. Soc Sci Med. 2006;62(4):866-76. doi: 10.1016/j.socscimed.2005.07.004. [PubMed: $16139936]$. 
25. Piroozi B, Moradi G, Nouri B, Mohamadi Bolbanabad A, Safari H. Catastrophic Health Expenditure After the Implementation of Health Sector Evolution Plan: A Case Study in the West of Iran. Int J Health Policy Manag. 2016;5(7):417-23. doi: 10.15171/ijhpm.2016.31. [PubMed: 27694669].

26. Limwattananon S, Tangcharoensathien V, Prakongsai P. Catastrophic and poverty impacts of health payments: results from national household surveys in Thailand. Bull World Health Organ. 2007;85(8):600-6. [PubMed: 17768518].

27. Yardim MS, Cilingiroglu N, Yardim N. Financial protection in health in Turkey: the effects of the Health Transformation Programme. Health Policy Plan. 2014;29(2):177-92. doi: 10.1093/heapol/czt002. [PubMed: 23411120].

28. Somkotra T, Lagrada LP. Payments for health care and its effect on catastrophe and impoverishment: experience from the transition to Universal Coverage in Thailand. Soc Sci Med. 2008;67(12):2027-35. doi: 10.1016/j.socscimed.2008.09.047. [PubMed:18952336].

29. Nguyen H, Ivers R, Jan S, Pham C. Cost of surgery and catastrophic expenditure in people admitted to hospital for injuries: estimates from a cohort study in Vietnam. Lancet. 2015;385 Suppl 2:S50. doi: 10.1016/S0140-6736(15)60845-5. [PubMed: 26313100].

30. Gotsadze G, Zoidze A, Rukhadze N. Household catastrophic health expenditure: evidence from Georgia and its policy implications. BMC Health Serv Res. 2009;9:69. doi: 10.1186/1472-6963-9-69. [PubMed:
19400939].

31. Rashad AS, Sharaf MF. Catastrophic and impoverishing effects of outof-pocket health expenditure: New evidence from Egypt. Am J Econ. 2015;5(5):526-33.

32. Somkotra T, Lagrada LP. Which households are at risk of catastrophic health spending: experience in Thailand after universal coverage. Health Aff (Millwood). 2009;28(3):w467-78. doi: 10.1377/hlthaff.28.3.w467. [PubMed: 19336470].

33. Rahman MM, Gilmour S, Saito E, Sultana P, Shibuya K. Health-related financial catastrophe, inequality and chronic illness in Bangladesh. PLoS One. 2013;8(2):e56873. doi: 10.1371/journal.pone.0056873. [PubMed: 23451102].

34. Sun J, Liabsuetrakul T, Fan Y, McNeil E. Protecting patients with cardiovascular diseases from catastrophic health expenditure and impoverishment by health finance reform. Trop Med Int Health. 2015;20(12):1846-54. doi: 10.1111/tmi.12611. [PubMed: 26426679].

35. Yardim MS, Cilingiroglu N, Yardim N. Catastrophic health expenditure and impoverishment in Turkey. Health Policy. 2010;94(1):26-33. doi: 10.1016/j.healthpol.2009.08.006. [PubMed: 19735960].

36. Lee JE, Shin HI, Do YK, Yang EJ. Catastrophic Health Expenditures for Households with Disabled Members: Evidence from the Korean Health Panel. J Korean Med Sci. 2016;31(3):336-44. doi: 10.3346/jkms.2016.31.3.336. [PubMed: 26955233]. 